\title{
MERODEADORES URBANOS EN UN MUNDO DIGITAL
}

\author{
Edgardo Berg
}

I

Ahora el viajero no viaja, lo viajan. Hubo tiempos en que desplazarse suponía cierto esfuerzo: caminar, trotar, montar, remar, timonear. Martín Caparrós

Nunca sabremos, con certeza, el contenido de más de las mil fichas que atesoraba Walter Benjamin en su maletín de cuero, mientras cruzaba los Pirineos. ${ }^{1}$ Por algunos fragmentos textuales, editados con posterioridad a su suicidio, intuimos que la experiencia de la ciudad moderna era el campo problemático básico de sus apuntes ensayísticos. Esa experiencia de la modernidad al modo de una capa sedimentada de vivencias, como lo demuestran algunos de sus textos, era articulada por la figura del flâneur, protagonista y merodeador por excelencia de la París de Baudelaire. ${ }^{2} \mathrm{Su}$

\footnotetext{
${ }^{1}$ En una de las hipótesis más difundidas de las investigaciones biográficas sobre el autor, se suele afirmar que Walter Benjamin, huyendo de los nazis, se suicida en la noche del 26 de setiembre de 1940, ingiriendo una sobredosis de morfina, la droga letal en forma de tableta que llevaba en las palmas de sus manos, en una habitación de un hotel en la localidad catalana de Port Bou, comarca costera y fronteriza de Francia convertida, por ese entonces, en ruina y escombros bajo los efectos devastadores de los bombardeos franquistas en la Guerra Civil. Ver Ingrid y Konrad Scheurmann (ed): Para Walter Benjamin, 3 vols. Bonn: ASKI, Inter Naciones 1994 (edición en castellano, inglés y alemán).

${ }^{2}$ En el trabajo sobre Baudelaire, surgido entre 1937 y 1939, Iluminaciones/2 (Baudelaire). Un poeta en el esplendor del capitalismo (1972) se puede ver un modelo en miniatura del
} 
actividad callejera (una flânerie, un paseo o un vagabundeo) presuponía, al mismo tiempo, una dialéctica de la mirada (sus ojos hendidos sobre el espectáculo urbano de la modernidad) como también una forma singularísima de acceder al sentido de esa experiencia (plano cognitivo de su disposición ambulatoria). Paulatinamente y con el correr del tiempo, la figura del flâneur, tanto social como literaria, se ha esfumado como el recuerdo de una experiencia histórica llena de sentido. ${ }^{3}$

Si para Walter Benjamin, el flâneur (personaje decimonónico por excelencia) habitaba las calles como si ellas mismas fueran su privilegiado recinto, ahora, en nuestra contemporaneidad, podemos advertir cómo en las grandes ciudades y en algunas capitales latinoamericanas, los nuevos parias sociales -los desclasados y los moradores del detritus del capitalismo avanzado- se sirven de las calles como si fueran su propio hábitat (su dormitorio, living o baño), bajo la celosa vigilancia del poder político y policial de turno (lo que es lo mismo).

Mientras que el desprevenido peatón actual (que ya no es un flâneur) se halla acosado y a merced del chillido disonante y del ruido predatorio de los automóviles y autobuses, los nuevos humillados y ofendidos que olvida o niega el capitalismo actual, en muchos centros capitalinos han ocupado, ciertamente, en otro contexto cultural e histórico, el lugar que

libro inconcluso de Los pasajes. Para una ampliación de las perspectivas de lectura del corpus benjaminiano, se puede consultar Walter Benjamin. Libro de los pasajes. Madrid: Ediciones Akal, 2005, edición en castellano de Rolf Tiedemann basada en Das PasagenWerk. Frankfurt am Main: SuhrkampVerlag, 1982.

3 Caminar no es necesariamente ser un flâneur. Insistentemente, en algunos análisis y lecturas críticas de escritores contemporáneos, cuando aparece relacionado, en tal o cual obra, un centro urbano (metrópolis), una multitud o un paseante, se suele recurrir a conceptos diseminados en los escritos de Walter Benjamin. En esos ensayos contemporáneos, por lo general de crítica literaria y cultural, se puede advertir cierto uso anacrónico y descontextualizado de algunas categorías que impregnaron las reflexiones ensayísticas del filósofo berlinés. En este sentido, Beatriz Sarlo, con justeza y precisión, nos advierte en su conocido ensayo "Olvidar a Benjamin" (200o), de cierta moda y abuso crítico de ciertas nociones benjaminianas: "Paseantes que se desconocen y se ignoran, extranjeros, marginales, conspiradores, dandies, coleccionistas, asesinos, panoramas, galerías, escaparates, maniquíes, modernidad y ruinas de la modernidad, shopping centers y autopistas. Un murmullo donde las palabras flâneur y flânerie se usan como inesperados sinónimos de prácticamente cualquier movimiento que tenga lugar en los espacios públicos. Se habla de la flânerie en ciudades donde, por definición, sería imposible la existencia del flâneur" (SARLO 2000: 78). Cfr. Beatriz Sarlo. Siete ensayos sobre Walter Benjamin. México: FCE, 200o; ver también de Martín Kohan, Zona urbana. Ensayo de lectura de Walter Benjamin. Buenos Aires: Norma, 2004. 
antaño tenía el flâneur, como en la París que retrató, con precisión y tan bellamente, Walter Benjamin.

Los nuevos medios electrónicos de comunicación y la todavía persistente televisión por cable ofrecen una modalidad óptica reglada y empaquetada (remedo deflacionario y similar en parte a la experiencia del antiguo voyeur); como si fuera, más bien, la evanescente experiencia turística de un viaje diseñado por una empresa de turno.

Así como el antiguo salteador de caminos, en el mejor de los casos, se ha convertido, en el actual "enjambre" mediático, en un experto digitalizador de transferencias bancarias (donde su lugar o residencia versátil es ahora el home banking); o en su desdén y manía cultural, en un acopiador de links y en un coleccionista de páginas web que luego transcribirá, sin ninguna mediación, en sus escritos; el antiguo flâneur se ha difumado y extinguido para siempre. ${ }^{4} \mathrm{Su}$ antiguo campo perceptual (urbano) y su peculiar mirada sólo persiste como una rémora o atadura literaria del pasado. Hablar hoy de flâneur (de su acción, una excursión a pie o una flânería) es por lo menos un anacronismo deliberado o una ingeniosa boutade.

Como afirma, con razón, Susan Bück Morss (1995), el momento utópico del flâneur ha desaparecido y como figura específica, que encarnaba socialmente una actitud perceptual frente al espectáculo de la experiencia moderna, ha sido devorada; ya sea por la sociedad de consumo de masas como, también, por las nuevas formas tecnológicas de visibilidad egotistas y narcisistas (un tránsito que podríamos recorrer velozmente y sin ninguna mediación del twitter al facebook).

En un mundo conectado a través de las vías de la información electrónica, provistas por la red de redes, ya no hay lugar para aquel paseante ocioso y despreocupado que se sentía en la ciudad (en la ciudad de París) como en su casa y capturaba, en sus recorridos y pasajes, la belleza fugitiva de la modernidad. En la ciudades contemporáneas no hay sitio para ningún deslumbramiento, ni para ninguna revelación irrepetible y única (llámese epifanía o iluminación profana; sea en tono joyceano o benjaminiano).

${ }_{4}$ Uso el término acuñado por el filósofo coreano Byung-Chul Han en su libro En el enjambre. Barcelona: Herder Editorial, 2014. 
¿Cómo hacer en la actualidad para convertir y transformar la materia de nuestros paseos y caminatas por una ciudad en la experiencia de una historia comunicable? ¿Cómo encontrarles sentido en un mundo regido por los mapas en red y las comunicaciones rápidas e instantáneas? ¿Cómo darles forma novelística a las historias que no cierran y se mantienen en suspenso como apuntes y garabatos apenas delineados en una libreta de apuntes? ¿Qué se conserva como resto de esa experiencia en la libreta migrante que remitimos a los comienzos de la escritura de un autor?

El escritor argentino Sergio Chejfec ha sabido construir, a lo largo del tiempo, una poética única y singular, a partir de la inscripción de una grafía del camino, donde el paseo y los itinerarios por diversos escenarios urbanos definen gran parte de su narrativa. Ya sea en los recorridos de sus personajes que, como letras de un alfabeto o piezas de un juego, intercambian y desplazan sus vidas o en los desplazamientos de la figura del narrador, muchas veces, desteñido por el sin sentido o el agotamiento. Si los períodos largos y dilatados, con sus paréntesis, pausas reflexivas y líneas verbales interrumpidas y vueltas a ritmar, marcan los signos de dicción y locución de Chejfec, sus personajes y narradores piensan andando; o ensayan y representan sus vidas al andar.

En este sentido, podríamos decir, con Michel De Certeau (1998, p. 109-110), que, en sus textos, "el acto de caminar es al sistema urbano lo que la enunciación (el speech act) es a la lengua o a los enunciados realizados". Las secuencias narrativas, las retóricas caminantes y las figuras del desplazamiento (los caminos, los paseos, los itinerarios y las idas y vueltas de sus personajes) presuponen un modo de entender la literatura y un recorte singular de los objetos de la experiencia literaria (los sistemas de referencia, la topografía de franjas móviles, las coordenadas espacio-temporales y la relación narrador-personajes). Se podría decir que toda historia que cuenta o narra Chejfec es una danza de pasos por la ciudad; un relato de un paseo o una caminata a medida que los pies de sus personajes la ejecutan. Y al ejecutar el paseo o la caminata, sus textos se mueven tensos entre la realización y el experimento, entre la resolución y el ensayo, siempre sumergidos sobre un pasado que persiste como resto pero amenazado por las señales que indican su posible devastación.

En este sentido, quizás la eficacia simbólica de las ficciones de Chejfec haya que buscarla en esa distancia estética que hace afilar los ritmos y la duración de sus frases; una demora o un retraso narrativo que, bajo 
el lento fluir de las palabras, va hilando un presente indefinidamente extensible en múltiples tiempos posibles. Una narración viajera, si se quiere, que apuesta a las formas especulativas del relato y que no avanza por continuidad o sucesión temporal; sino, más bien, en espiral, a través de los retrocesos, las pausas y las detenciones de un peculiar fraseo, estableciendo, en su inconfundible compás, una inédita alianza entre pensamientos, ideas y conceptos.

A menudo, sus pobladores, personajes o narradores, conservan el placer de vagabundear, quizás como una manía extemporánea o un desdén anacrónico; y deambulan, extrañados, sobre ciudades gemelas e indiferenciadas o atraviesan territorios yertos y desolados que hacen repensar la antigua idea de la ciudad en tanto civitas 5 .

Cuando la idea de nacionalidad o de geografía local parece desteñirse o evaporarse, los paseantes o viajeros crónicos (Barroso en El aire [1992], el narrador y Delia en Boca de Lobo [200o], Félix en Los incompletos [2004], el protagonista a punto de cumplir cincuenta años en Mis dos mundos [2008], Félix y Rose en La Experiencia dramática [2012], o los personajes de algunos de sus relatos recientes de Modo linterna [2013]), se enfrentan, como si fuera la última experiencia plausible de ser registrada, con los restos y ruinas de un paisaje urbano en vías de disolución. O sólo caminan, singularizándose en tanto sujetos, al asumir el paseo o la caminata como una manera de posicionarse (en tanto anclaje físico, verbal y lingüístico) sobre los no lugares (los espacios homogéneos y monótonos) que van transitando.

Se podría decir que las historias que cuenta Chejfec siempre se inician al ras del suelo y, al pasear, sus personajes inscriben su lugar de enunciación. Un modo de experimentar la ciudad cuando los espacios urbanos, al extrañarse, van perdiendo sus antiguos rostros, sus contornos

\footnotetext{
${ }^{5}$ Desde su etapa clásica y hasta por lo menos principios del siglo XX, la ciudad siempre ha sido pensada, con ligeras variantes y modulaciones, en su triple dimensión urbanística: ya sea como urbs (con sus edificios, calles e infraestructura), como civitas (es decir a partir del uso del espacio público, en tanto realidad social construida por los propios ciudadanos) y como polis (en tanto ordenamiento jurídico y unidad política-administrativa). Las transformaciones globales y la persistente mundialización de los espacios urbanos disuelven los criterios clásicos de su ordenamiento y modifican los modos de percepción de la ciudad. Ver Marshall Bermann. Todo lo sólido se desvanece en el aire. Madrid: Siglo XXI, 1988; Richard Sennett. Carne y piedra. El cuerpo y la ciudad en la civilización occidental. Madrid: Alianza Editorial, 1997 y Michel de Certeau: "Walking in the city", en The practice of everyday life, chapter 11. Berkeley and Los Angeles: University of California Press, 1988.
} 
y fronteras previsibles. A su vez, al asumir el tiempo de las demoras y los retardos, la narración espacializa los registros crónicos y las diversas duraciones. Y si como huella o cristal del tiempo, los textos de Chejfec parecen no olvidar los pretéritos pasos, las nuevas tecnologías modifican las imágenes urbanas en su proyección digital y transforman los modos de percepción (sea en su deterioro y corrosión, sea en su proyección digital como mapa o guía); extendiendo y reduplicando el movimiento físico de sus protagonistas sobre la geografía urbana.

Y si los personajes de Chejfec, a menudo, se des-figuran, pierden sus rostros y rasgos de identidad o se insinúan como líneas punteadas de un boceto apenas perfilado, también las ciudades por donde deambulan -sea Buenos Aires, Moscú, Caracas, Mérida, Maracay, París, Nueva York o Nueva Jersey- parecen vaciarse de sentido y olvidar su pasado, como si asistiésemos a un inevitable proceso de homogenización (presidida por la lógica del parecido y de la reduplicación) (SASSEN, 1999). Sin embargo, a pesar del olvido y el deterioro, sus personajes seguirán caminando obstinados, aun cuando la indagación del sentido de esa experiencia (entre lo vivido y lo imaginado, entre lo real y lo virtual) esté marcada por la expropiación, el tedio o el desamparo.

\section{III}

En las más recientes novelas y relatos de Chejfec, las nuevas tecnologías entran en escena modificando y transformando la experiencia y la antigua percepción del espacio urbano. Es así como en las novelas Mis dos mundos (2008) y La experiencia dramática (2012) se ejemplifica el paulatino adelgazamiento de la experiencia como el sin sentido o la imposibilidad de comunicación entre sus personajes, atravesados por un drama cotidiano que apenas comprenden.

Solemos asociar los primeros intentos narrativos de Chejfec con ciertas zonas de experimentación abiertas por Juan José Saer, ya sea en sus novelas y narraciones breves como en sus excursiones poéticas; sin embargo, ahora, con Mis dos mundos el autor parece acercarse a ciertos mecanismos propios de la ficción aireana, al colocar como materia literaria la disolución de la experiencia del paseo (propia de la modernidad) y llevar la historia narrada al borde de la decepción o el fracaso. Como si sus novelas al desplegarse, con sus vueltas y rodeos, con sus pausas reflexivas y sus pensamientos en movimiento, se fueran disipando o extinguiéndose. 
No es casual, en este sentido, la cita, más o menos encubierta, más o menos explícita, que abre la novela y que refiere el narrador a punto de cumplir cincuenta años: "Quedan pocos días hasta un nuevo cumpleaños, y si decido comenzar de este modo es porque dos amigos a través de sus libros me hicieron ver que estas fechas pueden ser motivo de reflexión, y de excusa o de justificación, sobre el tiempo vivido"(2008, p.7). Así comienza la novela, aludiendo como homenaje implícito a Cumpleaños (2001) de César Aira y a Una luna. Diario de hiperviaje (2009) de Martín Caparrós, ambas emparentadas, entre la visibilidad o el viaje por los ciclos de la luna, con el mismo tema del comienzo.

Cifra de los instantes transcurridos en una vida y registro de otros viajes, la novela Mis dos mundos es, al mismo tiempo, la historia de un caminante como el relato de las vicisitudes de un escritor a punto de cumplir cincuenta años. La figura del narrador, como viajero a pie o paseante solitario, vuelve a ser protagonista en la novela. Invitado a participar en una Feria del Libro en una ciudad del sur de Brasil y luego de haber consumado su conferencia sobre literatura, producto del hastío o la indiferencia, sale a caminar y recorre distintos sitios locales hasta que, finalmente, emprende una larga caminata en busca de un parque: " [...] esa mancha verde [...] derramada como una tinta, apenas contenida”, que percibe el narrador en el mapa que le han facilitado en la recepción del hotel donde se aloja (CHEJFEC 2008, p. 14).

Ya sea como pregnancia del pasado familiar en los objetos que perduran como restos (el encendedor del abuelo o el largavista del padre como legado imposible en su descendencia), en el tintineo invertido que proyectan las espaldas de una olvidadiza ciudad europea (así el reloj pulsera observado por el narrador en un local que avanza de derecha a izquierda) o como un punto en un espejo, que entrelaza la lejanía momentánea de dos historias (la escena reduplicada en un banco entre el narrador y el anciano, ambos contemplando el lago del parque), la novela Mis dos mundos puede ser pensada en los entre-tiempos que se intersectan (la paradójica simultaneidad entre el pasado, presente y futuro).

Pero también como mapa de un viaje o cuaderno de apuntes escondido en un morral, la novela es la frágil relación o el tenso y dispar diálogo entre la identidad y la memoria, entre lo natural y lo artificial, entre lo individual y colectivo; o entre los modos personales y privados y los hábitos sociales indiferenciados. Si los mapas abstractos y virtuales no dejan de ser una representación defectuosa y anómala de la ciudad, la 
gran mancha verde que representa el parque puede ser pensada, también, como réplica del acto novelesco. En este sentido, no es casual que el parque funcione como motivo y catalizador del proceso de escritura. Una construcción artificial que imita, en su versión domesticada y en escala, el mundo silvestre o la naturaleza salvaje. Dicho de otro modo, la novela es un viaje a pie o un apunte en una libreta que mide, si se quiere, los grados de la devastación y la declinación de la experiencia. ${ }^{6}$

Ahora, siguiendo el recorrido que sugieren los mapas virtuales y los vínculos digitales, el narrador aparece moldeado por los nuevos medios de comunicación electrónica, modificando sus modos itinerantes y deambulando por una ciudad sin esperar recuperar, en la pausa de una detención o en el alto del camino, el sentido de una experiencia o su reconstrucción narrativa. Cuando el antiguo espesor material del paseo ha declinado, los recorridos urbanos se transmutan o metamorfosean en la forma de los hipervínculos de Internet:

Mi impresión es que durante las caminatas me gana una sensibilidad digital, desplegante. No lo digo con orgullo, sino con contrariedad: es de lo peor que me podía pasar porque afecta mi faceta intuitiva y se impone como una condena. Los puntos o circunstancias donde concentro mi atención toman la forma de enlaces de internet: no solamente se trata de los objetos mismos de observación, en general urbanos, pertenecientes al mundo de la calle o de la vida en general de la ciudad, precisos en sus formatos y discriminados del entorno, también significan la asociación que sugieren, la reminiscencia de lo percibido como relacionado, como parecido o directamente como distinto, o sea, en cualquier aspecto que uno pueda establecer esos vínculos. (CHEJFEC,2008,p.25).

Vaciada de sentido y de misterio, la manía ambulatoria del narrador queda, ahora, reducida solo a un tic social y físico, ya que ninguna sorpresa o revelación cabe en sus continuos itinerarios y desplazamientos. Barrios, mercados y locales comerciales sellados por la repetición y la desidia o centros urbanos con sus parques artificiales contribuyen a pensar en una economía urbana proclive a la semejanza y a la repetición:

\footnotetext{
${ }^{6}$ Mis dos mundos parece evocar con referencias más precisas que en otros textos del autor a la Feria del Libro de Porto Alegre de Brasil, una de las Ferias más multitudinarias del Cono Sur (se calcula más de dos millones de asistentes por año), realizada desde 1955 en el mes de Octubre; asimismo, el Parque, donde inicia su recorrido ambulatorio el narrador de la novela, remitiría al Parque Farroupilha (también conocido como Parque Redenção) en la misma ciudad capital del Estado de Rio Grande do Sul.
} 
Remate de Males, Campinas-SP, v. 37, n. 2, p. 875-889, jul./dez. 2017 - 883

Si bien durante todos mis años disfruté de las caminatas y lo sigo haciendo hasta el punto de sentirlas como un componente esencial de mi vida, una costumbre sin la cual no me reconocería a mí mismo, de un tiempo a esta parte caminar se ha ido vaciando de significado, o por lo menos de misterio, y a veces tan sólo me queda el antiguo entusiasmo, que por lo general se disipa a la media hora como un humo demasiado liviano. A veces he pensado que son las mismas ciudades las que tienen la culpa. La uniformidad visual y económica, las grandes cadenas comerciales, las modas y los estilos transfronterizos, que relegan lo particular a un segundo plano, a un fondo borroso de colores envejecidos. (CHEJFEC 2008, p. 16).

Y en esa percepción sobre los nuevos estadios urbanos, presididos por los falsos parecidos y la homogenización de los sitios y lugares, el narrador en sus continuas detenciones, producidas por un pensamiento migrante y siempre en movimiento, inscribe a modo de homenaje, réquiem o simple acotación de sus recuerdos librescos, el fin de los antiguos caminantes: el dandy o el flâneur baudeleriano, el poeta trapero benjaminiano o el paseante walseriano como figuras literarias y, a la vez, sociales, se hallan agotadas y hoy están fuera de contexto: ${ }^{7}$

Me puse a pensar entonces en la cantidad de tiempo que llevo caminando. Años, décadas. En el caso de vivir demasiado más podría seguir sumando, porque si de algo estoy seguro es de que nunca dejaré de caminar. Sin embargo, aún con esta tremenda cantidad de recorrido en realidad ninguna caminata me ha brindado auténticas revelaciones. No ha sido en mi caso como en el pasado, cuando los caminantes sentían reencontrarse con algo que sólo se ponía de manifiesto en el trance de andar, o creían descubrir aspectos del mundo o relaciones en la naturaleza hasta ese momento ocultas. Yo nunca encontraré nada, sólo una vaga idea de lo novedoso o lo diferente, por otra parte bastante pasajera. (CHEJFEC, 2008 p. 55)

Habituado a los primeros métodos de búsqueda de Internet, azarosas y dubitativas, el narrador de Mis dos mundos conserva algo de esas previas aventuras digitales ("cuando el recorrido o la navegación a través de la red estaba menos regido por la fatalidad o la eficacia de los buscadores como lo están hoy, y uno debía derivar entre cosas parecidas, extravagantes o difusamente relacionadas", p.25); una experiencia que se vincula con la percepción imprecisa y ambigua de la ciudad, más próxima a las conexiones y enlaces evanescentes de la web.

${ }^{7}$ Me refiero obviamente al personaje de los microgramas de Robert Walser y, en especial, a su libro de 1917, El paseo. Madrid: Editorial Ciruela, Colección Libros del Tiempo, 2001. 
A la experiencia literalmente muda que le sobreviene al narrador en su estadía en el parque, paradójicamente imaginada y pensada como un coloquio frente a un auditorio de escuchas o a un concierto plural de receptores atentos (un par de cisnes inmensos y a pedal, un conjunto de peces, carpas y tortugas a orillas del lago como interlocutores presentes), le sucede una escena de interrupción (como si fuera la parábola de un jardín convertido en un laberinto borgeano) que entrecruza el vector temporal como una línea de encuentro entre la figura del narrador y un anciano (la imagen del intruso en el banco como el otro yo futuro del narrador).

El temor a la exposición o de exhibir, en tanto gesto público, una anotación en una libreta o en un cuaderno personal, separa, irremediablemente, la vida cotidiana y social de un escritor (ese alter ego o doble perfecto que sostiene y traza el nombre propio de Chejfec como matriz y moneda de cambio de la inscripción autobiográfica) con la privacidad de la literatura. Pensada como improductiva o bajo el peso de la inutilidad, la literatura, en el contexto de los discursos sociales hegemónicos, sella un hiato y marca el imposible encuentro entre la vida y la literatura; entre lo común y lo singular, entre el yo secreto y los ademanes públicos de un escritor. Si bien co-extensibles y, a su vez, paralelos, los dos mundos se manifiestan y viven en su inevitable disyunción. Entre la proximidad y el escamoteo, uno de los últimos pasajes narrativos de la novela graba e imprime la escena de la escritura. Sentado en una mesa de un café, más precisamente en el café del Lago de Porto Alegre, entre los murmullos de la gente y el chillido disonante de platos y tazas, el narrador imagina dibujar siluetas y garabatos en su libreta personal; al mismo tiempo que juega a la desafectación de su rol y figura de narrador (un deseo de invisibilidad ansiada y manifiesta):

Durante mucho tiempo consideré la escritura como una labor privada, que sin embargo debe hacerse pública en algún momento porque de lo contrario sería muy difícil que subsista, en particular y en general. Pero la vergüenza no sólo derivaba de dedicarme a algo privado ante la vista de todos, sino también de hacer algo improductivo, una cosa medianamente inútil y bastante banal. [...] Por lo tanto mi principal preocupación no pasaba por superar mis defectos y mis insensatas ilusiones de escritura, sino por no ser descubierto. A eso se reducía la vida, podía decir, mientras me acercaba a un cumpleaños crucial: a no ser descubierto. (CHEJFEC, 2008, p. 121-122).

El pudor o el acoso de sentirse observado impide conservar la reserva y colocar la experiencia de la escritura en su propia ajenidad (mantener la distancia que evite la identificación autobiográfica para forzar el acto 
ilocutivo de la enunciación en las palabras novelescas). Sin embargo, en la interrupción del rodeo ambulatorio de frases y figuras, curvatura que nos remite al campo explorativo del autor, el último pasaje novelesco se asocia a las anteriores páginas que convocan el nombre propio de William Kentridge $^{8}$. Como una escena de reduplicación textual o en espejo, el narrador, en tanto figura de autor, se convierte en lector de su propio proceso de escritura. Como imágenes en movimiento y bocetos en pleno proceso de construcción, los dibujos y animaciones de Kentridge parecen nombrar la apuesta narrativa de Chejfec; y pueden ser vistos como pasajes que unen dos acciones de figuración y escritura, análogas y simétricas .9

\section{IV}

La experiencia dramática (2012) es la última novela publicada hasta el momento por Sergio Chejfec y bien podría pensarse como la historia o el relato de una representación; o quizás de su fracaso e imposibilidad. En una ciudad descripta con escasas referencias espaciales (avenidas, bares, un río que divide en dos la ciudad) y que se mantiene a lo largo de la novela como innominada (aunque parezca en sus rasgos visibles la suma de fragmentos de distintas ciudades, algunas de sus marcaciones

\footnotetext{
${ }^{8}$ Sentado en la terraza del Café do Lago y contemplando las serenas aguas del lago, el narrador se siente, por un instante, observado por un cisne a pedal donde van un padre con su hija; como si los ojos del bote en forma de cisne lo mirara y no apartara su vista de su rostro. La posibilidad de encontrar un sentido a su pensamiento o a su divagación (vista por momentos como "una exageración dramática"), lo llevarán al narrador a asociar esa escena personal (imaginaria o conjetural) con el arte del dibujante sudafricano William Kentridge. Es así como se detendrá y ensayará modos de intelección posible sobre la mirada de Félix, personaje de los dibujos animados compuestos en grafito por Kentridge. Una mirada y un punto de vista en renovación continua, podríamos decir, al modo de un haz de luz o una energía disparada hacia un objeto que pronto se difuminará. Y en este sentido, no es casual en Chejfec que tanto sus personajes como su narrador (el protagonista dominante en sus últimas novelas), al igual que Félix Teitlebaum y Soho Eckstein, parezcan bocetos difumados, siluetas en movimiento, al modo de los dibujos y diseños del artista sudafricano Kentridge, que evoca como homenaje la novela Mis dos mundos. Ver páginas 102-108.

9 Para la obra de William Kentridge puede consultarse el volumen colectivo realizado por el Macba (Museu d'art contemporani de Barcelona, 1999); también William KentridgeMuseum of Modern Art Moma.org /interactives/williamkentridge 2010/flashCheck.htm, la entrevista concedida por el autor a Dominique Rodríguez, "Señoras y señores, con ustedes, William Kentridge”, en la Revista Dinners (28/7/2014) y, entre otras, puede verse su película de animación Felix in exile en YouTube.
} 
topográficas visibles permiten pensar en alguna ciudad de Estados Unidos, más precisamente en New York), dos amigos, una actriz vocacional y un extranjero, se encuentran rutinariamente en algunos bares de la ciudad y comparten una serie recorridos por distintos puntos y escenarios del paisaje urbano. Como acción recurrente de los personajes, la caminata, al igual que en casi todas las novelas del autor, produce una sintaxis propia derivada de los cambios espaciales y de los paisajes entrevistos. En esa serie de encuentros entre Rose y Félix (la actriz y el extranjero), la narración se despliega en una serie de pensamientos, conjeturas e hipótesis sobre sus propias historias de vida; muchas veces falseadas e inventadas o imposibles de recordar.

Espectadores solitarios de una ciudad, los dos paseantes miran el entorno urbano que recorren; $y$, al mirar, la ciudad se desdobla y se multiplica en perspectivas: entre el acoso paranoico y la duplicidad de caminos. Rose, mientras pasea, cree ser observada, registrada y grabada por una cámara; Félix, entre las perspectivas aéreas que le proporcionan los mapas de Google y sus traslados bien al ras del suelo, prolonga e intensifica sus recorridos.

Al modo de un obstáculo en su historia personal, Rose no puede representar un ejercicio teatral límite propuesto por su profesor de actuación ("la experiencia más dramática en su vida"); mientras Félix inventa y teatraliza una vida en sus diálogos paseantes con Rose, cuenta una historia falsa pero creíble (la vida con su esposa). Y en esos diálogos migratorios, los personajes mantienen e intercambian sus historias, suspendidas y vueltas a contar, una y otra vez como esquirlas o ramalazos dubitativos del recuerdo, mientras el pasado vuelve en forma de conjetura y permanente vacilación (las historias de Rose y su marido, de Félix y su esposa o la historia del marido de B, entre otras). Vidas contadas o falseadas. Puntos y líneas sobre un escenario urbano; lugares o piezas, como si sus historias personales, la vida que representan, fuera un relato escénico (con sus gestos, mímica y posturas) y la novela, un guión o un libreto teatral manejado por un tramoyista o un prestidigitador.

Ahora, los mapas digitales (los google maps) transforman las caminatas de Félix; duplicando y segmentando el recorrido como si un rastro digital o "un halo electrónico" hubiera dejado su impresión e inscribiera su señal en el trayecto urbano. Y ese recorrido hecho con los mapas que titilan sobre la pantalla de una computadora es tan decisivo e irrevocable como cualquier desplazamiento real y material sobre la 
ciudad. Entre lo material y lo virtual, entre lo real y lo digital, los mapas virtuales que obsesionan a Félix extienden y desdoblan los planos, al mismo tiempo que modifican la experiencia de una caminata o de un paseo, anticipando el futuro en la seguridad virtual de un simulacro o de un paisaje domesticado.

Con impresiones disímiles, paralelas y contrapuestas de una misma ciudad -espacio de aventura o de la infancia, ciudad real o irreal-, ambos personajes se pliegan en el camino como si fueran una suerte de dueto impar.

$\mathrm{Si}$, ahora, el caminar parece haberse transformado en una especie de representación o proyección digital, la ciudad, al mismo tiempo, es contemplada por Rose o Félix como un escenario, donde los protagonistas inventan una vida o ensayan diversas modalidades de una experiencia, tan artificial como verdadera. En la puntuación suspendida, en las cesaciones momentáneas o en los paréntesis del diálogo, la ciudad se manifiesta siempre partida en dos, al modo de una imagen urbana de tiempos y espacios superpuestos. Es así como sobre el final de la novela, en uno de los tantos devaneos pedestres (que implican también las impresiones contrapuestas y los vagabundeos mentales de ambos personajes), Rose y Félix se dirigen hacia una antigua área ribereña de la ciudad que, al contener entrelazados secuencias de espacios y tiempos diferentes, parecen ser la cifra de un pasado que aún no ha terminado y se conserva en sus restos y ruinas. Un paisaje postindustrial de la ciudad, si se quiere, con sus semáforos, vías y ramales en desuso, con sus galpones y desechos industriales abandonados.

Ese paseo y ese itinerario por una ciudad de una ancha avenida y un canal, también conlleva los escenarios de la desolación y de la pérdida. Si Rose rechaza las imágenes de la devastación y la belleza incierta que produce el paisaje en pleno proceso de demolición, Félix, por su parte, "cae en una especie de trance y se somete a un extraño sentimiento de inspiración elegíaca”, cuando percibe o cree percibir la realidad, vista como una caja de resonancias de su propio estadio de incertidumbre y abandono (CHEJFEC, 2012, p. 130).

Cuando ambos personajes regresen y abandonen esa zona de intemperie y desamparo, caminando por una calle lateral de la ciudad y dejando el antiguo barrio industrial, volverán a percibir la pauperización en el trayecto urbano. Pero ahora, esos signos de abandono y pobreza los percibirán adheridos a los dedos laboriosos de las manos, al observar el 
cuidado con que dos sujetos anónimos revuelven, al costado de la vereda, varias bolsas de basura.

\section{REFERENCIAS}

AAVV. William Kentridge. Barcelona: Museu d’art contemporani de Barcelona. 1999.

BENJAMIN, Walter. Iluminaciones/2 (Baudelaire). Un poeta en el esplendor del capitalismo. Madrid: Taurus, 1972.

BENJAMIN, Walter. Libro de los pasajes. Madrid: Ediciones Akal, 2005.

BUCK-MORSS, Susan. Dialéctica de la mirada Walter Benjamin y el proyecto de los Pasajes. Madrid: Visor, 1995.

CAPARRÓS, Martín. Una luna. Diario de hiperviaje. Barcelona: Anagrama, 2009.

CHEJFEC, Sergio. El aire. Buenos Aires: Alfaguara, 1992.

CHEJFEC, Sergio. Los planetas. Buenos Aires: Alfaguara, 1999.

CHEJFEC, Sergio. Boca de lobo. Buenos Aires: Alfaguara, 2000.

CHEJFEC, Sergio. Los incompletos. Buenos Aires: Alfaguara, 2004.

CHEJFEC, Sergio. Mis dos mundos. Buenos Aires: Alfaguara, 2009.

CHEJFEC, Sergio. La experiencia dramática. Buenos Aires: Alfaguara, 2012.

CHEJFEC, Sergio. Modo linterna. Buenos Aires: Editorial Entropía, 2013.

CHEJFEC, Sergio. Prólogo. In: CARRERA, Arturo. Vigilámbulo. Poesía reunida. Buenos Aires: Adriana Hidalgo Editora, 2014.

DE CERTEAU, Michel. Andares de la ciudad. In: DE CERTEAU, Michel. La invención de lo cotidiano 1 Arte de hacer. México: Universidad Iberoamericana, 1980, pp. 109-110.

DE CERTEAU, Michel. Walking in the city. In: DE CERTEAU, Michel. The practice of everyday life. Berkeley and Los Angeles: University of California Press, 1988.

GROYS, Boris. Antinomies of Art and Culture. Modernity, Posmodernity, Contemporaneity. Duke: University Press. 2008.

HAN, Byung-Chul. En el enjambre. Barcelona: Herder Editorial, 2004.

KENTRIDGE, William. Felix in Exile. In: YouTube, 1994. 
Remate de Males, Campinas-SP, v. 37, n. 2, p. 875-889, jul./dez. 2017 - 889

KENTRIDGE, William. William Kentridge-Museum of Modern Art Moma.org/ interactives/williamkentridge/flashCheck.htm, 2010.

KOHAN, Martín. Zona urbana. Ensayo de lectura de Walter Benjamin. Buenos Aires: Norma, 2004.

RODRIGUEZ, Dominique: Señoras y señores, con ustedes, William Kentridge (entrevista). In: Revista Dinners, 28/7/2014.

SARLO, Beatriz. Siete ensayos sobre Walter Benjamin. México: FCE, 2000.

SASSEN, Saskia. La ciudad global. Nueva York, Londres, Tokio. Buenos Aires: Eudeba, 1999.

SCHEURMANN, Ingrid y Konrad (ed). Para Walter Benjamin, 3 vols. Bonn: ASKI, Inter Naciones (edición en castellano, inglés y alemán), 1994.

SENNETT, Richard. Carne y piedra. El cuerpo y la ciudad en la civilización occidental. Madrid: Alianza Editorial, 1997.

WALSER, Robert. El paseo. Madrid: Editorial Ciruela, Colección Libros del Tiempo, 2001. 